\title{
International
}

\section{APSA Workshops in the Middle East and North Africa}

T he second half ofAPSA's 2016 MENA Workshops program "Civil Society Revisited: Researching Associational Life in Comparative Perspective" was held September 18-22 in Amman, Jordan. The event was part of a multiyear initiative to support political science research and networking in the Arab Middle East and North Africa. Funded by Carnegie Corporation of New York, the MENA Workshops program is a major component of APSA's efforts to engage with political science communities outside the United States and support research networks linking US scholars with their colleagues overseas.

Together with a spring workshop in Beirut, Lebanon, the Amman program sought to revisit the concept of civil society in the wake of the Arab Uprisings. While there is broad agreement that civil society matters, the precise causal mechanisms by which it is believed to exert an influence remain understudied. As the region experiences upheavals and regime change, a wide range of actors with sometimes competing ideologies struggle to define and operationalize the mechanisms for securing durable political reform, social stability, and lasting peace. These changing state-society dynamics offer scholars a unique opportunity to reexamine-and potentially reconceptualize-traditional understandings of civil society.

After discussing an extensive set of readings at the Beirut Workshop, fellows used the interim months to develop an article-length manuscript related to the overall workshop theme. At the September program in Amman, fellows shared their work with colleagues for intense peer review and feedback. Additional sessions included professional development discussions related to publishing, grant writing, and networking. Following their participation in the five-month program, alumni received a three-year membership to APSA and are eligible to apply for small grant funding to advance their research.

Coleading the 2016 Workshops were Fateh Azzam (American University of Beirut and the Asfari Institute, Lebanon), Sandrine Gamblin (American University in Cairo, Egypt), Noora Lori (Boston University, USA), Richard Norton (Boston University, USA), and Denis Sullivan (Northeastern University, USA). In addition, participants included $25 \mathrm{PhD}$ students and early-career faculty from across the MENA region, Europe, and the United States.

Since 2013, APSA has organized eight workshops throughout the MENA region, with over 100 scholars having taken part in the program. The MENA Workshops program will continue in 2017 with a focus on networking alumni with the greater community of Middle East political science scholars and providing support for advancing their work towards publication. For more information, visit APSA's MENA Workshops website at http://web.apsanet.org/mena/.

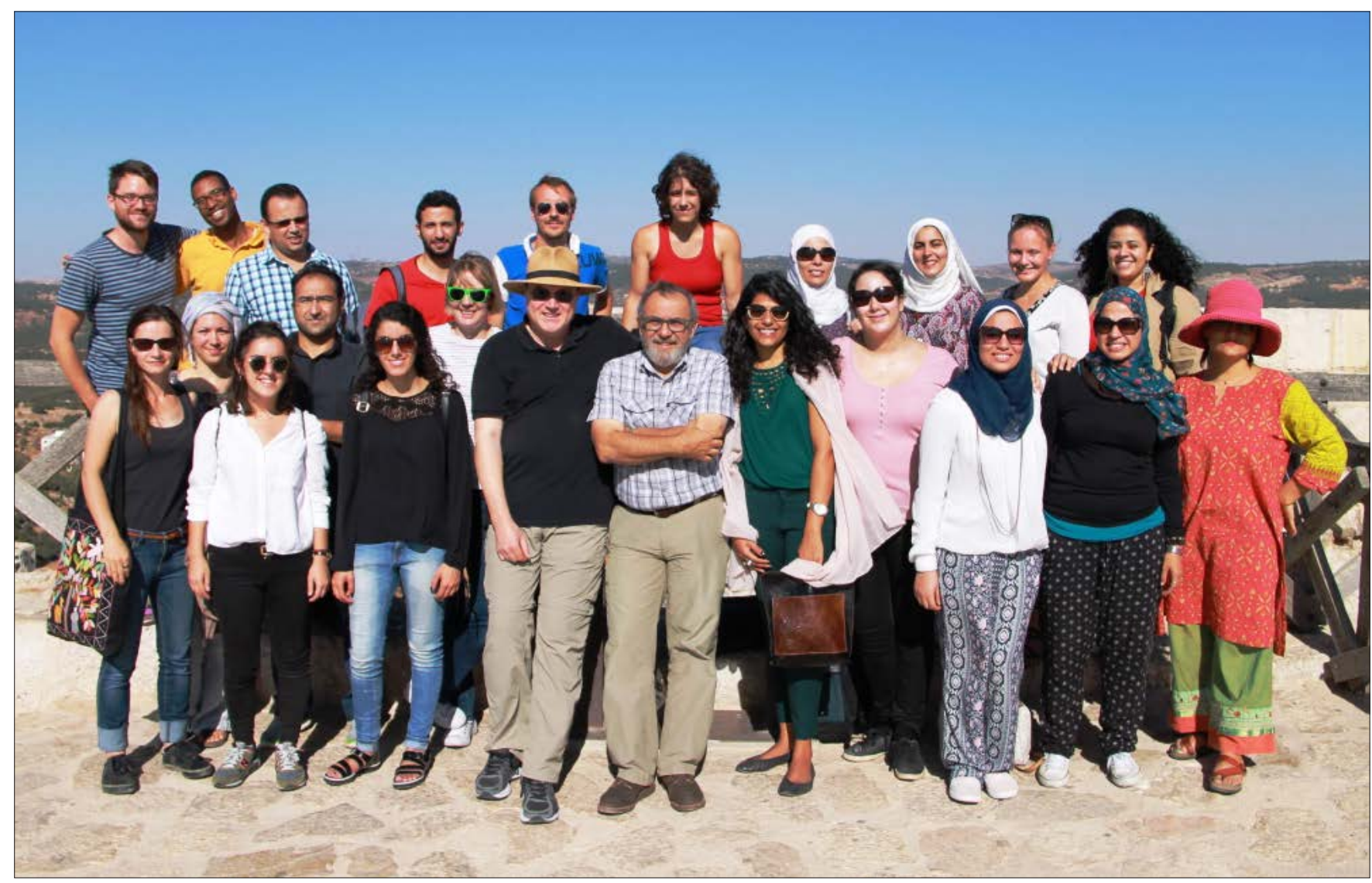

Fellows and leaders take a break during the September workshop in Amman to visit Ajloun Castle. 